\title{
A case of large sub mitral aneurysm with rheumatic heart disease
}

\author{
Anish Hirachan ${ }^{1}$, Gopi Prasad Hirachan², Bishal KC
}

1,3 Gautam Buddha Community Heart Hospital , Butwal

2 Gandaki Medical College, Pokhara

Corresponding Author: Anish Hirachan

Gautam Buddha Community Heart Hospital , Butwal

Email: hirachananish@gmail.com

Cite this article as: Hirachan A, Hirachan GP, KC B. A case of large sub mitral aneurysm with rheumatic heart disease. Nepalese Heart Journal 2018; 15(2): 39-40.

Received date: 8th August 2018

Accepted date: 13 th September 2018

\section{Abstract}

Sub mitral aneurysm is a very rare cardiac pathology with varied clinical manifestations. The disease process has been postulated to various mechanisms including mainly infection and inflammation. Here, we describe a young female with large submitral aneurysm presenting with rheumatic heart disease in the form of severe mitral regurgitation and aortic regurgitation.

Keywords: Rheumatic, submitral aneurysm.

\section{Introduction}

Submitral aneurysm is a rare cardiac pathology and is only noted in a few numbers of case series. Submitral aneurysm (SMA) was first described by Corvistart in 1812 and the first case was reported in 1962. SMA invariably occurs adjacent to the posterior annulus of the mitral valve. Here, we report a case of young female presenting with large submitral aneurysm in association with rheumatic heart disease.

\section{Case Report:}

A 24year old married female presented with the history of progressive breathlessness New York Heart Association (NYHA) Class II / III and palpitation since 6 month. She was evaluated at a local health center and was later referred for cardiomegaly and heart failure. On examination, she was thin built and poorly nourished. Her heart rate was 140/min regular, BP was 140/80 $\mathrm{mm}$ of $\mathrm{Hg}$, respiratory rate was $30 / \mathrm{min}$, jugular venous pressure (JVP) was raised, and bilateral pitting edema was present. Cardiovascular examination revealed displaced ill sustained apical impulse, systolic thrill and a Grade IV/VI loud pansystolic murmur at the apex along with an early diastolic murmur at the neo-aortic area. Other lab parameters were within normal limits. Chest X-ray revealed cardiomegaly with evidence of left atrial enlargement. On echocardiography, she had evidence of rheumatic heart disease in the form of thickened anterior mitral leaflet (AML) and posterior mitral leaflet (PML) of mitral valve along with thickened aortic cusps. Severe degree of mitral regurgitation (MR), moderate aortic regurgitation with dilated left atrium (LA) and left ventricle (LV) was evident. In addition, she had a large sub mitral aneurysm $(5.1 \times 3.6 \mathrm{~cm})$ in the posterior aspect of submitral region communicating with the left ventricle. Hence, she was referred for surgical repair of the aneurysm and mitral valve replacement/ repair.

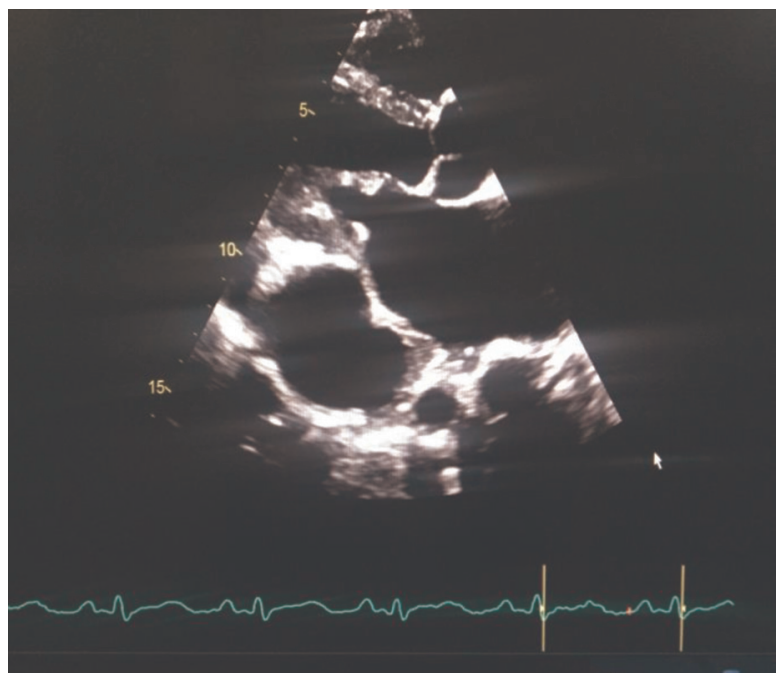

Fig A: Large submitral aneurysm posterior to $L V$

@Nepalese Heart Journal. Nepalese Heart Journal retains copyright and work is simultaneously licensed under Creative Commons Attribution License CC - BY 4.0 that allows others to share the work with an acknowledgement of the work's authorship and initial publication in this journal.

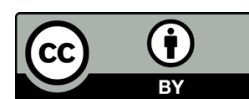




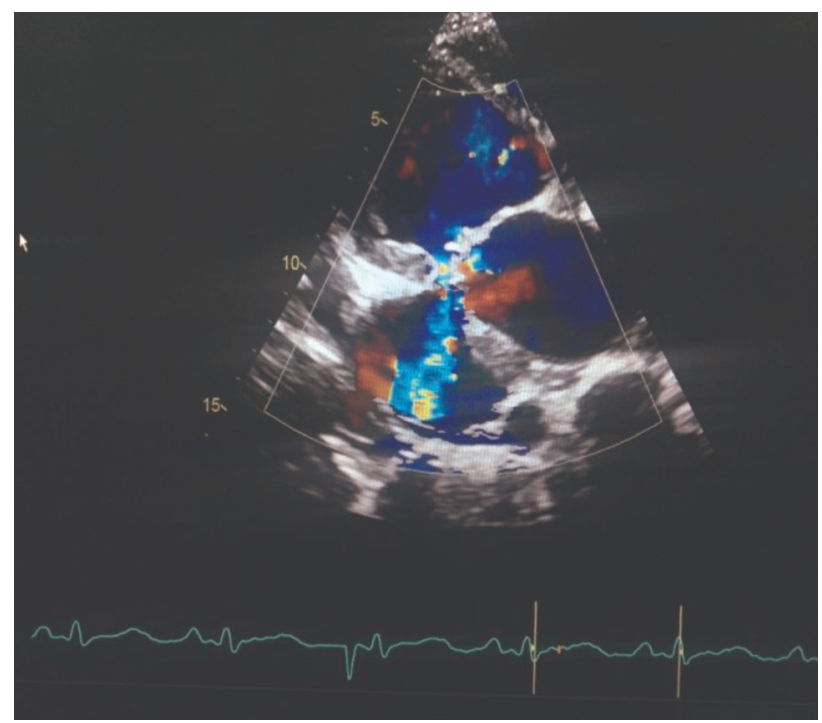

Fig B: Color Doppler showing flow into the cavity (Aneurysm)

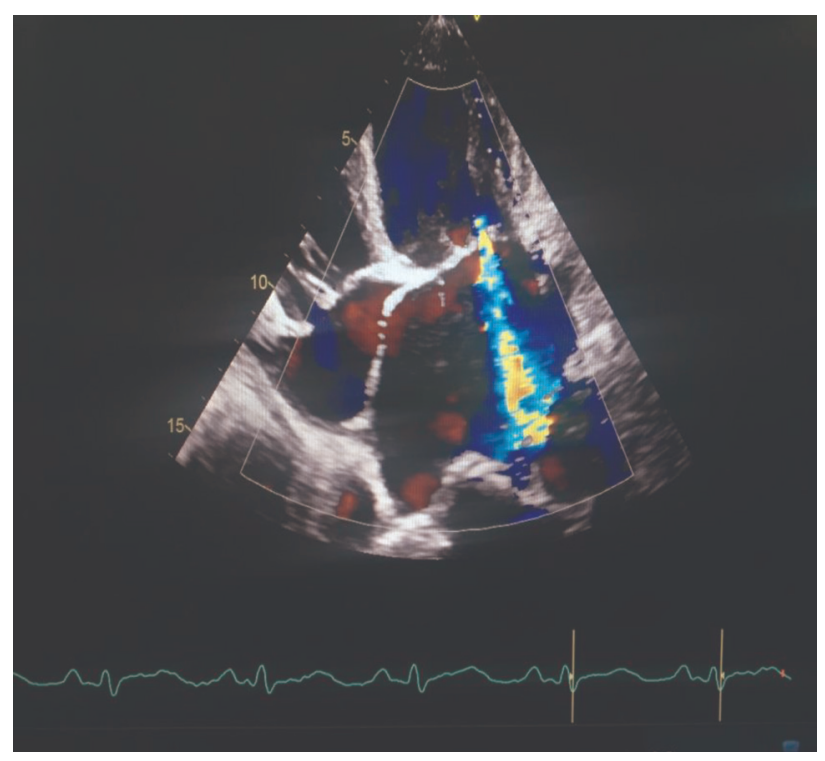

Fig C: $A 4 C$ view showing severe $M R$ jet with dilated left atrium

\section{Discussion :}

Submitral aneurysm is a rare cardiac pathology with varied etiologies among which infection, inflammation and trauma has been postulated as commonest. The infectious illnesses mentioned most often as possible causes of these types of aneurysms are syphilis and tuberculosis; whereas the non infectious and nontraumatic aneurysms support the suggestion that they could be due to the congenital defect of the valvar ring. ${ }^{1}$

Clinically, submitral aneurysms are characterized by cardiac insufficiency(heart failure), mitral insufficiency, and the absence of coronary artery disease associated with thromboembolic phenomena, cardiomyopathy and cardiac arrhythmias. ${ }^{2}$ Although it can present rarely with life threatening complications such as ventricular tachycardia caused by compression of the left main coronary artery, the most common presentation is severe mitral regurgitation. ${ }^{3}$ Diagnosis of submitral aneurysm is typically made in the 2 nd or 3 rd decade of life. Associated findings on presentation include severe mitral regurgitation, heart failure, systemic embolism, and sudden cardiac death. The basic pathology in these lesions has been described as a disjunction between the $\mathrm{LV}$ musculature and the left atrium-mitral valve region due to the disturbance of complex embryogenesis, which ties up the left atrium, LV and the mitral valve ensuring electrical isolation. ${ }^{4}$

Management of SMA involves initial medical stabilization with diuretics and afterload-reducing agents. Surgical repair is the definitive treatment and includes pericardial patch repair. ${ }^{5,6}$ This literature was highlighted basically to increase the awareness of this rare cardiac disorder among clinicians especially echocardiographers when they come across young patients with mitral regurgitation and heart failure. The case reported here is a rare association of rheumatic heart disease with mitral and aortic regurgitation along with large submitral aneurysm.

\section{Conflict of interest}

The authors do not have any conflict of interest including financial in publication of this article.

\section{References:}

1. Baruah DK, Kumar PN, Reddy GS, Babu VR. Submitral aneurysm of the left ventricle. Indian Heart Journal. 2012 Jan 1;64(1):77-9.

https://doi.org/10.1016/S0019-4832(12)60015-7

2. Ribeiro PJ, Mendes RG, Vicente WV et.al. Submitral left ventricular aneurysm. Case report and review of published Brazilian cases. Arquivos brasileiros de cardiologia. 2001 May;76(5):399-402. https://doi.org/10.1590/S0066-782X2001000500006

3. Vohra RS, Kadam DB, Kale NC. A case of submitral left ventricular aneurysm (SMA), presenting with acute rheumatic fever with HIV infection. Medical Journal of Dr. DY Patil University. 2014 Mar 1;7(2):225. https://doi.org/10.4103/0975-2870.126355

4. Antunes MD. Submitral left ventricular aneurysms. Correction by a new transatrial approach. The Journal of thoracic and cardiovascular surgery. 1987 Aug; 94(2):2415.

5. Nayak VM, Victor S. Sub-mitral membranous curtain: a potential anatomical basis for congenital sub-mitral aneurysms. Indian Journal of Thoracic and Cardiovascular Surgery. 2006 Oct 1;22(4):205-11. https://doi.org/10.1007/s12055-006-0003-4

6. Rose AG, Folb J, Sinclair-Smith CC, Schneider JW. Idiopathic annular submitral aneurysm associated with Takayasu's aortitis. A report of two cases. Arch Pathol Lab Med 1995;119:831-5. 